\title{
Experimental characterizations of a new solar air heater with packed-bed latent storage energy
}

\author{
Salwa Bouadila ${ }^{1}$, Safa Skouri, Mariem Lazaar \\ ' (The Research and Technology Center of Energy, The Thermal Processes Laboratory, Hammam Lif, B.P. 95, \\ 2050 Tunis, Tunisia)
}

\begin{abstract}
An experimental study was conducted to evaluate the thermal performance of a new solar air heater collector with a packed bed latent heat thermal energy storage system using PCM spherical capsules (SAHLSC). Using both first and second law analysis, the energetic and exegetic daily efficiencies were calculated for the SAHLSC operated in Closed/Opened and Opened cycle mode. The solar energy was stored in the packed bed through the diurnal period and extracted at night. The experimentally obtained results are used to analyze the performance of the system, based on temperature distribution in different parts of the collectors, absorbed, instantaneous stored and used thermal energy. Energy and exergy analysis were carried out to evaluate the SAHLSC efficiency. The net daily energy efficiency varied between $32 \%$ and $45 \%$. While the net daily exergy efficiency varied between $13 \%$ and $25 \%$.
\end{abstract}

Keywords: Latent heat storage; packed bed solar air heaters; thermal efficiency.

\section{Introduction}

The thermal energy can be stored as sensible heat, latent heat, reaction heat or combination of those forms. Many thermal storage energy systems are cited in literature [1-5], with applications in cogeneration, building and solar heating of water or air. The use of Phase Change Material (PCM) storage in a solar air heater is less common, the majority of the studies were numerical. Hence, authors $[6,7]$ used numerical tools to determine the solar air heating systems performance using PCM energy storage, to examine the effect of the latent heat and the PCM melting temperature and to identify the optimum phase change materials physical properties. Ghoneim et al [8] evaluated the theoretical performance of solar heating collectors with PCM and sensible heat storage in water and in air. Fath [9] used a thermosyphon solar air heater with a series of packed tubes containing a PCM with different melting temperatures of $61,51,43$ and $32{ }^{\circ} \mathrm{C}$. The tubes were arranged parallel to each other in order to make a flat-plate-style configuration with air flowing over and under them simultaneously. This work will address packed beds of encapsulated PCM in the spherical capsules system which is one of the most effective and compact latent thermal energy systems [10-12]. In order to provide an amount of storage heat nocturnal use we will present an analytical and experimental investigation of a new Solar Air Heater with Latent Storage Collector (SAHLSC) using spherical capsules as a packed bed absorber. The SAHLSC designed and realized in the Research and Technology Center of Energy (CRTEn) in Tunisia. of the paper, should explain the nature of the problem, previous work, purpose, and the contribution of the paper. The contents of each section may be provided to understand easily about the paper.

\section{Hdescription of The Experimental Set-Up And Measurement Procedure}

An experimental set-up of the solar air heater latent storage collector was designed and constructed to investigate the charging and discharging processes. The experiments were performed during March month in CRTEn. A schematic arrangement of the solar air heater with phase change energy storage using spherical capsules is given in Fig. 1. The experimental apparatus consists of a packed bed absorber formed of spherical capsules with a black coating and fixed with steel matrix. The PCM is confined inside spherical capsules. The packed bed absorber is the most important component of the solar air heater collector, which absorbs the sun radiations and stores the solar thermal energy as sensible heat and latent heat. The length, the width and the total volume of the collector are $2 \mathrm{~m}, 1 \mathrm{~m}$ and $0.28 \mathrm{~m}^{3}$, respectively. A $0.004 \mathrm{~m}$ thick transparent glass cover was placed $0.015 \mathrm{~m}$ apart from the absorber. A $0.05 \mathrm{~m}$ thick polyurethane insulation, with heat conductivity 0.028 $\mathrm{W} / \mathrm{m} . \mathrm{K}$, is placed in the bottom of the collector to decrease thermal losses through the bottom. 


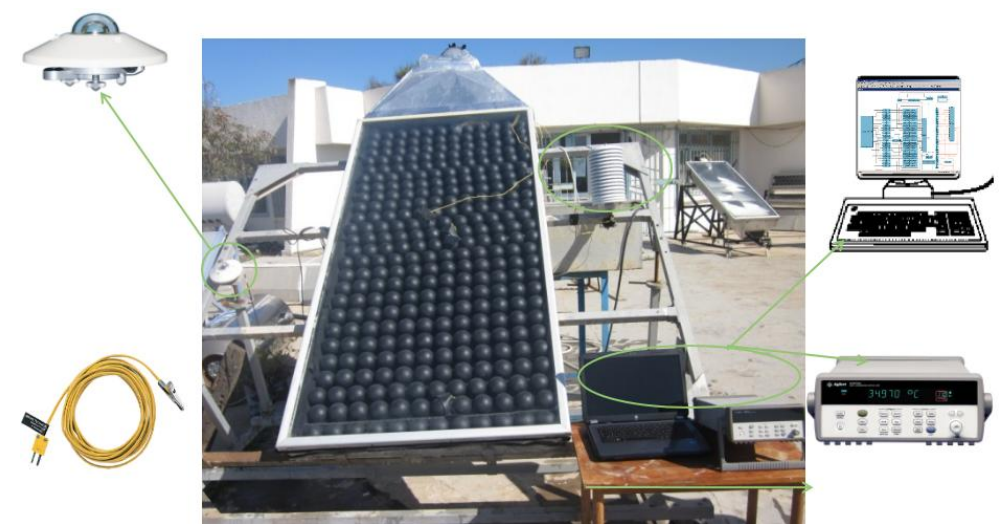

Fig.1. Experimental set-up of the SAHLSC.

The charging process starts when the absorber is exposed to the solar radiation (from 9:00 to 16:00). It was measured by a Kipp and Zonen pyranometer placed facing to the south at the same inclination of the absorber. During this process, air inlet and outlet openings are closed. The discharging process starts from 16:00 to 9:00 (the next day) (Fig. 2). The inlet and outlet air openings are opened. A fan used to blow the air at a fixed speed equal to $1 \mathrm{~ms}^{-1}$. The inlet and outlet air temperatures of the SAHLSC, respectively, were measured with K-type thermocouples. All the measuring instruments were connected to a multi-channel digital Agilent 34970A Data Acquisition. The experimental values are recorded every $5 \mathrm{~min}$.

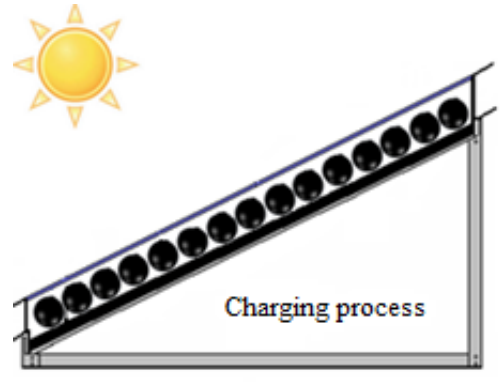

(a)

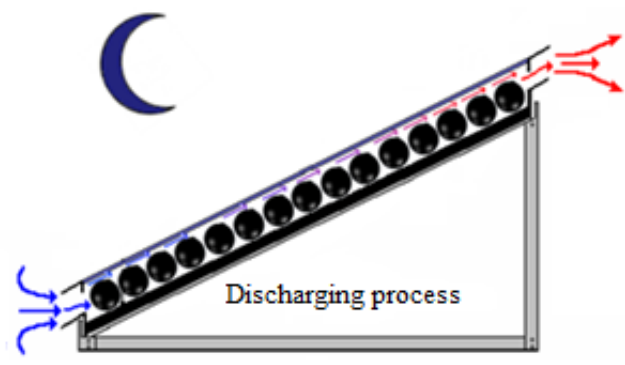

(b)

Fig. 2. Charging and discharging process.

\section{Energy Analysis}

The energy analysis presented in this section is mainly based on the first law of thermodynamics. The theoretical model employed for the study of the SAHLSC consists of using a thermal energy balance during both the charging and discharging phases:

$$
Q_{A}=Q_{u}+Q_{s t}+Q_{l o s}
$$

Where $Q_{A}, Q_{u}, Q_{s t}$, and $Q_{l o s}$ are the absorbed, useful, stored and lost energy, respectively.

Based on Duffie et al. [13], the useful heat gain from the collector is:

$Q_{u}=m C_{p}\left(T_{\text {out }}-T_{\text {in }}\right)$

$V_{a v}$ are average air velocity and $S$ are the sectional area of the duct at the inlet of the solar air heater.

The radiation absorbed flux of the absorber packed-bed is defined as:

$$
Q_{A}=A_{p}(\alpha \tau) I_{T}
$$

Where $(\alpha \tau)$ is the effective product transmittance-absorptance that is equal with the optical efficiency $\left(\eta_{0}\right)$. The stored heat flux during the charging and discharging phases is given by:

$$
\begin{aligned}
& Q_{c h}=\left[m_{P C M} C_{p, s}\left(T_{m}-\bar{T}_{i n i_{-} c h, P C M}\right)+m_{P C M} \mathrm{~L}+m_{P C M} C_{p, l}\left(\bar{T}_{f i n_{-} c h, P C M}-T_{m}\right)\right] / \Delta t_{c h} \\
& Q_{d i s}=\left[m_{P C M} C_{p, l}\left(T_{m}-\bar{T}_{f i n_{-} d i s, P C M}\right)+m_{P C M} \mathrm{~L}+m_{P C M} C_{p, s}\left(\bar{T}_{i n_{-} d i s, P C M}-T_{m}\right)\right] / \Delta t_{d i s}
\end{aligned}
$$


The lost heat flux is given by relation (7), $U_{\text {los }}$ is the collector overall heat loss coefficient. The thermal energy lost from the collector to the surroundings by conduction, convection and infrared radiation. $U_{l o s}$ is equal to the sum of energy loss through the top $\left(U_{t}\right)$, bottom $\left(U_{b}\right)$ and edges $\left(U_{e}\right)$ of the collectors given below [13]:

$$
Q_{\text {los }}=U_{\text {los }} A_{c}\left(\overline{T_{P}}-T_{a}\right)
$$

$U_{\text {los }}=U_{t}+U_{b}+U_{e}$

The thermal efficiency based on the first law of thermodynamics is defined as the ratio between the useful energy and the solar radiation incident on the collector:

$\eta=Q_{u} / A_{c} I_{T}$

The daily average thermal efficiency $(\eta)$ of the SAHLSC is the ratio of the desired energy output during the discharging process to the total energy input during the charging process.

$\eta=\left(\int_{d i s} Q_{d i s}\right) /\left(\int_{c h} A_{c} I_{T}\right)$

\section{Results And Discussion}

To Fig. 3 shows the outlet SAHLSC temperature, wind velocity and ambient temperature as a function of day times. A great part of the absorbed solar heat was stored inside the PCM. The 17 March is characterized by severely solar radiation fluctuation with ambient air temperatures from $16^{\circ} \mathrm{C}$, and wind velocity vary from 1 to $7 \mathrm{~ms}^{-1}$. We noted that the temperature into the solar collector is ranging from $25^{\circ} \mathrm{C}$ to $35^{\circ} \mathrm{C}$ and the PCM is charged during the closed cycle (Fig. 3). In fact, during the discharging periods; after 16:00 (local time), the outlet temperature decrease progressively at the beginning of the opened cycle due to the coldness of the liquid PCM (sensible heat). After 2 hours, the temperature remains constant; nearly $18{ }^{\circ} \mathrm{C}$, during the solidification process (latent heat).

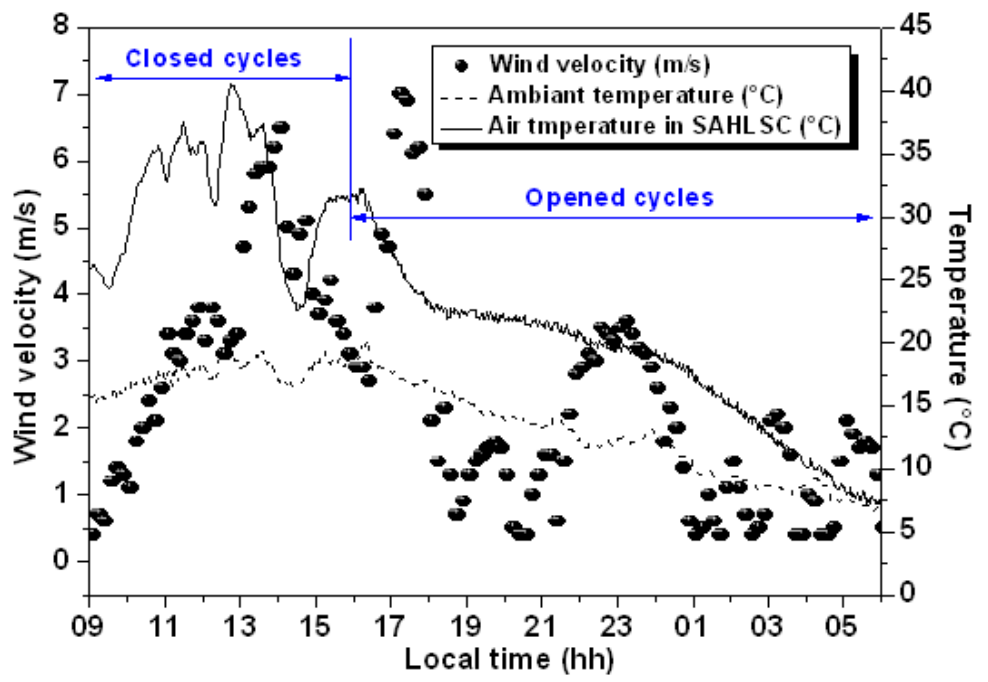

Fig. 3 Ambient temperature, outlet SAHLSC temperature and wind velocity as a function of times.

Variations of absorbed, useful and stored energy are presented in Fig. 4 for different times under climatic conditions characterized by severely solar radiation fluctuation. It is observed that during the initial period of charging, the instantaneous heat stored increases with insolation and towards a maximum value of 1 $\mathrm{kW}$ at 13:00, we noted that at this time the absorbed heat is $2.2 \mathrm{~kW}, 45 \%$ of the solar energy is stored in the collector. During the charging process, Fig. 4 shows the instantaneous stored heat fluctuate at the same time as insolation. As the discharging process proceeds, the PCM starts solidifying and the used heat is uniform for a longer period. The uniform value of the used heat is about $200 \mathrm{~W} / \mathrm{m}^{2}$ during 11 hours, we can also conclude that the useful heat was not affected by the solar radiations fluctuation during the day. This is the major advantage of a latent storage solar air heater, where a uniform discharging process is possible for a longer period, which will be useful for many applications of heating. 


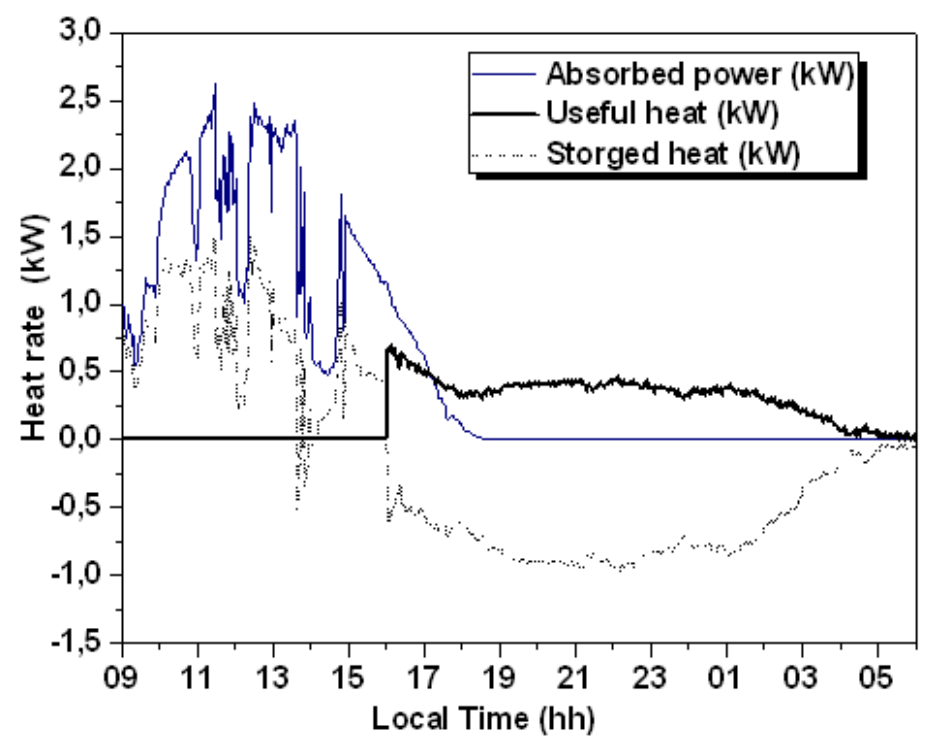

Fig. 4. Absorbed, useful and stored heat rates as a function of times

The energy analysis of the SAHLSC was performed with data obtained from the experiments. Fig. 5 shows the values of the daily energy and exergy efficiency as function of days from 19 to 30 March. The daily average energy efficiency changed between $32 \%$ and $45 \%$. While the daily exergy efficiency varied between $13 \%$ and $25 \%$. The daily average value of energy efficiencies is about $40 \%$.

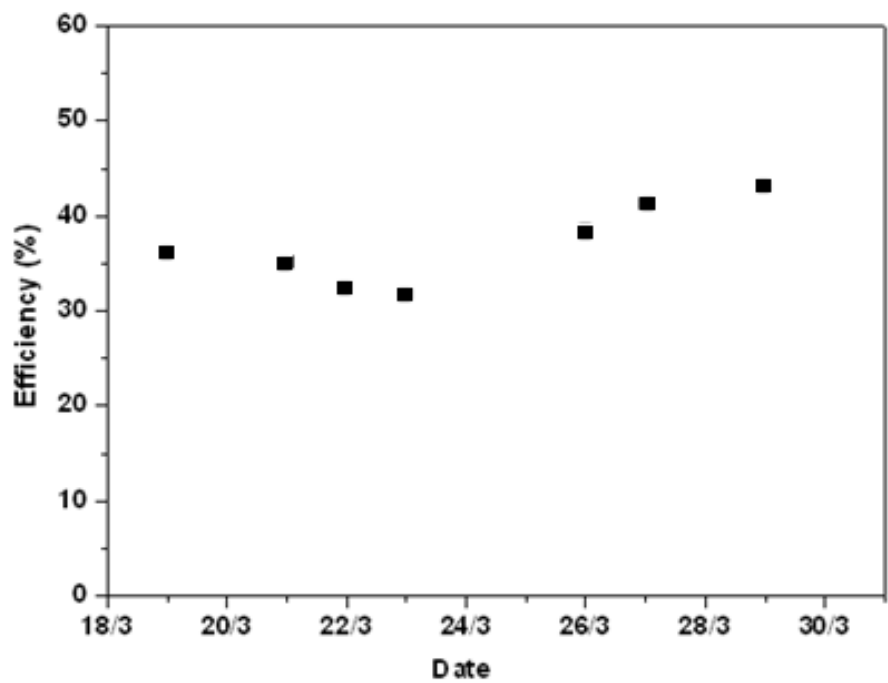

Fig. 5. Daily energy efficiency as a function of days (19 March to 30 March).

\section{Conclusion}

The solar air heater remains a uniform useful heat during the discharging process. The value of the heat was $200 \mathrm{~W} / \mathrm{m}^{2}$ during 11 hours at night. This useful heat was not affected by the severally global solar radiation fluctuation during the charging mode. The net daily energy efficiency of the SAHLSC varied between $32 \%$ and $45 \%$.

\footnotetext{
Nomenclature

Symbole

$A_{c} \quad$ surface area of the collector, $m^{2}$

$A_{p} \quad$ surface area of the absorber, $m^{2}$

$C_{p} \quad$ specific heat, $J / \mathrm{kg}^{\circ} \mathrm{C}$

$I_{T} \quad$ solar radiation, $\mathrm{W} / \mathrm{m}^{2}$

$m$ mass flow rate, $\mathrm{kg} / \mathrm{s}$
} 

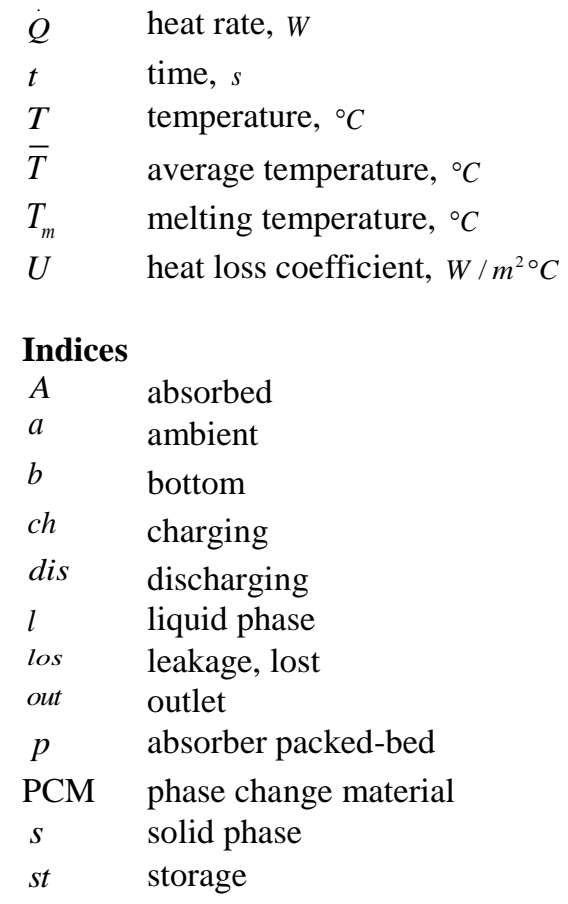

\section{Acknowledgements}

The authors wish to thank the Research and Technology Center of Energy in Borj Cédria, Tunisia (CRTEn) for the help to achieve this work.

\section{References}

[1] A.K Bhargava., A solar water heater based on phase-changing material. Applied Energy, Volume 14, pp 197-209, 1983;

[2] S.M Hasnain., Review on sustainable thermal energy storage technologies Part 1: Heat storage materials and techniques. Energy Conversion and Management, Volume 39, pp 1127-1138, 1998.

[3] M.M.Farid, A.M. Khudhair, S.A.K. Razack, S. Al-Hallaj, A review on phase change energy storage: Materials and applications. Energy Conversion and Management, Volume 45, pp 1597-1615, 2004.

[4] I. Dincer, M.A. Rosen, Thermal energy storage: System and applications. John Wiley and Sons, 2006.

[5] Y. Tian, C.Y. Zhao, A review of solar collectors and thermal energy storage in solar thermal applications. Applied Energy, Volume 104, pp 538-553, 2013.

[6] D.J Morrison., S.I. Abdel-khalil, Effects of phase-change energy storage on the performance of air-based and liquidbased solar heating systems. Solar Energy, Volume 20, pp 57-67, 1978.

[7] J.J. Jurinak, S.I. Adbel-Khalik, Properties optimization for phase-change energy storage in air-based solar heating systems. Solar Energy, Volume 21, pp 377-83, 1978.

[8] A.A. Ghoneim, Klein S.A., The effect of phase change material properties on the performance of solar air based heating systems. Solar Energy, Volume 42, pp 441-447, 1989.

[9] H.E.S. Fath, Transient analysis of thermosyphon solar air heater with built-in latent heat thermal energy storage system. Renewable Energy, Volume 6, pp 119-124, 1995.

[10] K. Cho, Choi S.H., Thermal characteristics of paraffin in a spherical capsule during freezing and melting processes. Intentional Journal of Heat and Mass Transfer, Volume 43, pp 3183-3196, 2000.

[11] I.W. Eames, K.T. Adref, Freezing and melting of water in spherical enclosures of the type used in thermal (ice) storage systems. Applied Thermal Energy, Volume 22, pp 22:733-745, 2002.

[12] K.A.R. Ismail, J.R. Henriquez, T.M Silva., A parametric study on ice formation inside spherical capsule. Intentional Journal of Thermal Science, Volume 42, pp 881-887, 2003.

[13] J.A., Duffie, W.A. Beckman, Solar Engineering of Thermal Processes. 2nd ed. John Wiley and Sons. New York: USA;1991. 